\title{
Meteorologically Defined Limits to Reduction in the Variability of Outputs from a Coupled Wind Farm System in the Central US
}

\section{Citation}

Junling Huang, Xi Lu and Michael B. McElroy. 2014. Meteorologically defined limits to reduction in the variability of outputs from a coupled wind farm system in the Central US. Renewable Energy 62 (Feb): 331-340.

\section{Published Version}

doi:10.1016/j.renene.2013.07.022

\section{Permanent link}

http://nrs.harvard.edu/urn-3:HUL.InstRepos:10981611

\section{Terms of Use}

This article was downloaded from Harvard University's DASH repository, and is made available under the terms and conditions applicable to Open Access Policy Articles, as set forth at http:// nrs.harvard.edu/urn-3:HUL.InstRepos:dash.current.terms-of-use\#OAP

\section{Share Your Story}

The Harvard community has made this article openly available.

Please share how this access benefits you. Submit a story.

\section{Accessibility}


Meteorologically defined limits to reduction in the variability of outputs from a coupled wind farm system in the Central US

Junling Huang, ${ }^{a}$ Xi Lu, ${ }^{a}$ Michael B. McElroy ${ }^{\text {a, b, * }}$

${ }^{a}$ School of Engineering and Applied Sciences, Harvard University, Cambridge, MA 02138, USA

${ }^{\mathrm{b}}$ Department of Earth and Planetary Sciences, Harvard University, Cambridge, MA 02138, USA

*Corresponding author

Tel.: 617-494-4359

Email:mbm@seas.harvard.edu 


\begin{abstract}
Studies suggest that onshore wind resources in the contiguous US could readily accommodate present and anticipated future US demand for electricity. The problem with the output from a single wind farm located in any particular region is that it is variable on time scales ranging from minutes to days posing difficulties for incorporating relevant outputs into an integrated power system. The high frequency (shorter than once per day) variability of contributions from individual wind farms is determined mainly by locally generated small scale boundary layer. The low frequency variability (longer than once per day) is associated with the passage of transient waves in the atmosphere with a characteristic time scale of several days. Using 5 years of assimilated wind data, we show that the high frequency variability of wind-generated power can be significantly reduced by coupling outputs from 5-10 wind farms distributed uniformly over a ten state region of the Central US in this study. More than $95 \%$ of the remaining variability of the coupled system is concentrated at time scales longer than a day, allowing operators to take advantage of multi-day weather forecasts in scheduling projected contributions from wind.
\end{abstract}

Keywords: interconnection; transient waves; meteorologically defined limits 


\section{INTRODUCTION}

Some 13,131 MW of wind generating capacity were added to the US electrical system in 2012, an increase of $93 \%$ compared with the same period in 2011. Total installed capacity for wind power in the U.S. amounted to $60,007 \mathrm{MW}$ by the end of 2012 , equal to approximately $6 \%$ of total U.S. power generating capacity. Lu et al [1] argued that an onshore network of GE 2.5 MW turbines installed in the contiguous U.S. could supply as much as 16 times total current U.S. demand for electricity. A study by the U.S. Department of Energy concluded that wind could account economically for $20 \%$ of total U.S. demand for electricity by 2030 [2], while Short et al [3] argued that as much as $25 \%$ of demand could be met feasibly by 2050 .

The current electrical system requires an essentially instantaneous balance of supply and demand dictated largely by the latter. Opportunities for storage of electricity when supply exceeds demand are limited, while options to modulate demand are also minimal. Base load demand is accommodated in the present system mainly by a combination of contributions from nuclear and coal with an additional contribution in some regions of the country from hydro. Gas-fired systems provide the fast response required to adjust to short and intermediate-term fluctuations in demand. The challenge posed by the need to incorporate a significant source from wind relates to the intrinsic variability of this source. Production of electricity from an individual wind farm can vary over a wide range on time scales as brief as minutes or as extensive as days or even longer [4].

A number of authors have pointed to the advantages that could be realized by combining outputs from a series of spatially separated wind farms [5-14]. Katzenstein et al. [10] reported a frequency dependent analysis of the smoothing in output that could be obtained by coupling up 
to 20 spatially separated wind farms in Texas. Linking up as few as 4 of these farms resulted in a reduction of $87 \%$ in the variance of hourly output as compared to that associated with a single installation. Adding the remaining 16 facilities resulted in only a minimal reduction in the overall variance (8\%). Kempton et al. [11], using 5 years of wind data from 11 meteorological stations distributed over $2500 \mathrm{~km}$ of the US East Coast, concluded that when outputs from an array of wind farms distributed along the coast were coupled, the output from the interconnected system was much more stable than that from any individual location. The correlation between individual station outputs decreased exponentially on a scale of $430 \mathrm{~km}$ as determined by properties of the related synoptic weather systems. Archer and Jacobson [12] considered the benefits of connecting wind farms from up to 19 sites in the mid west characterized by annually averaged wind speeds in excess of $6.9 \mathrm{~m} \mathrm{~s}^{-1}$ (class 3 or greater) at $80 \mathrm{~m}$. They concluded that on average $30 \%$, as much as $47 \%$, of the connected output could be deployed as reliable base-load power. Hart and Jacobson [13] found that combining complementary renewable resources, such as wind, solar and hydro, can help mitigate the variability problems associated with any one of these options. Fertig et al. [14] reported that interconnecting wind plants on a large scale would reduce the most extreme hour-to-hour changes in energy output and increase the percentage of reliable power. Previous studies exploring the issue of interconnections focused on the statistical analysis of wind data and did not explicitly address the physical factors responsible for the observed variation of surface winds.

This study addresses the issue of interconnection with specific attention to the physical factors that determine the temporal variability of winds in the near surface region of the atmosphere. Surface winds are influenced by the passage of transient waves and by boundary layer turbulence triggered by these waves [15-17]. An understanding of these physical factors can help interpret 
the findings of the previous studies. We consider specifically how transient waves influence instantaneous power output. We show that there is a limit to the extent that the intrinsic variability of power output can be reduced, and quantify how this reduction in variability responds to different levels of wind farm coupling.

\section{MATERIALS AND METHODS}

2.1 MERRA Reanalysis Data. This study was based on meteorological data from the Modern Era Retrospective-analysis for Research and Applications (MERRA) compilation covering the period Dec 2002 to Nov 2007. Boundary layer winds and geopotential heights included in this compilation were obtained on the basis of retrospective analysis of global meteorological data using Version 5.2.0 of the GEOS-5 DAS. Geopotential heights are available on a 3-hour basis with a resolution of $5 / 4{ }^{\circ}$ latitude by $5 / 4{ }^{\circ}$ longitude, while boundary layer winds are calculated hourly at a resolution of $1 / 2^{\circ}$ latitude by $2 / 3^{\circ}$ longitude. Data on surface roughness are also included in the dataset. The MERRA assimilation was adopted in the present analysis to take advantage of the relatively high spatial and temporal resolution available with this product.

2.2 Calculation of Wind Power. In calculating the potential electricity generated from wind, we chose to use power curves and technical parameters for the GE 2.5 MW turbines (rated wind speed $12.0 \mathrm{~m} / \mathrm{s}$, cut-in wind speed $3.5 \mathrm{~m} / \mathrm{s}$, and cut-out speed $25.0 \mathrm{~m} / \mathrm{s}$ ). The power curve of the wind turbine, provided by the manufacturer, available at http://www.ge-energy.com and included in Supporting Information (SI), defines the variation of power output as a function of wind speed. The usefulness of adopting the GE 2.5 MW power curve in analyzing wind power has been tested and justified elsewhere [18]. 
Boundary layer wind data are available on an hourly basis for altitudes of $2 \mathrm{~m}, 10 \mathrm{~m}$, and $50 \mathrm{~m}$. We chose to extrapolate the results from $50 \mathrm{~m}$ to estimate the wind speed at $100 \mathrm{~m}$ as appropriate for the hub height of the GE 2.5 MW turbines. The extrapolation was implemented using the logarithmic relationship appropriate for a neutral stability condition assuming a surface roughness of $\mathrm{Z}_{0}$ :

$$
V_{100}=V_{50} \times \frac{\ln \left(Z / Z_{0}\right)}{\ln \left(Z_{50} / Z_{0}\right)}
$$

where $V_{100}$ and $V_{50}$ indicate hourly values for the wind speed at $100 \mathrm{~m}$ and $50 \mathrm{~m}$ respectively, $\mathrm{Z}$ and $Z_{50}$ define the elevation of the turbine hub $(100 \mathrm{~m})$ and the reference $50 \mathrm{~m}$ altitude, and $\mathrm{Z}_{0}$ defines the surface roughness length, values for which are taken from the MERRA tabulation.

The power yield at any given time is expressed as a fraction of the rated power potential of the installed turbines. This quantity, the instantaneous capacity factor $(\mathrm{CF})$, is given by

$$
C F=\frac{P_{\text {real }}}{P_{\text {rated }}}
$$

where $P_{\text {real }}$ denotes the power actually realized, and $\mathrm{P}_{\text {rated }}$ refers to the power that could have been realized had conditions permitted the turbine to operate at its name plate capacity. The instantaneous capacity factors presented here are calculated as functions of time on an hourly basis.

2.3 Region of Interest. The earlier analyses $[12,14]$ are extended to explore the advantages that could be realized by coupling an array of wind farms over the wind-rich Central Plains region of the US. For present purposes we identify the region of interest as the combined states of Montana, Wyoming, North Dakota, South Dakota, Minnesota, Wisconsin, Iowa, Illinois, Missouri, Nebraska, Kansas, Oklahoma, and Texas. To illustrate the influence of transient waves 
and the benefit of interconnection, we select ten farms, one per state, distributed over the study region as indicated in Figure 1. Though these wind farms are located in three different electrical interconnections (Western Interconnection, Eastern Interconnection, and ECORT), it is assumed in this study that all of the wind farms located within the Central Plains region could be coupled.

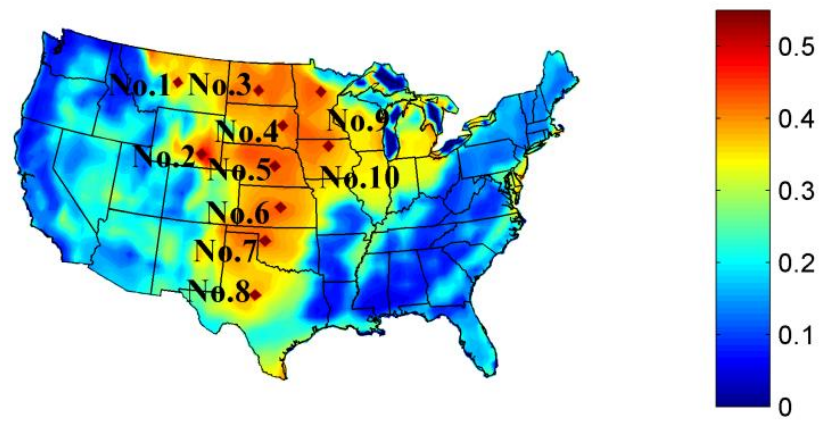

Fig. 1. Color coded values for capacity factor (CF) as a function of position averaged over the 5 year period Dec 12002 to Nov 30 2007. Positions of individual locations considered in this paper are indicated by the dots, one per state.

\section{Results}

\subsection{Meteorology of wind energy in US}

\subsubsection{Examination of transient waves}

The boundary layer wind, e.g. $100 \mathrm{~m}$ wind, as indicated earlier, is controlled by two factors: conditions in the free atmosphere which vary on a time scale of a few days with a spatial scale of about $1000 \mathrm{~km}$, and conditions at the surface which are responsible for small scale and fast varying turbulence in the boundary layer $[15,16]$. Figure 2 a shows the variation of the vertical profile of the flux kinetic energy per square meter, $1 / 2 \rho \cdot \mathrm{V}^{3}$ ( $\rho$ represents the density of air at 
different layers of the atmosphere, and $\mathrm{V}$ denotes the wind speed) in the free atmosphere between $870 \mathrm{hPa}$ (approximately $1.5 \mathrm{~km}$ above sea level) to $500 \mathrm{hPa}$ (approximately $5.5 \mathrm{~km}$ above sea level) above a grid cell near the City of Chicago $\left(42^{\circ} \mathrm{N}, 88.7^{\circ} \mathrm{W}\right)$ between Dec 12004 and Feb 28 2005. Figure $2 b$ presents the variation of CF that would be realized for a wind farm located in the vicinity of Chicago $\left(42^{\circ} \mathrm{N}, 88.7^{\circ} \mathrm{W}\right)$ over the same period. While strong winds in the free atmosphere generally lead to strong winds near the surface, and consequently high instantaneous values of $\mathrm{CF}$, conditions at the surface, as indicated, introduce random turbulent fluctuations that contribute significantly to the high frequency variability of the boundary layer wind.
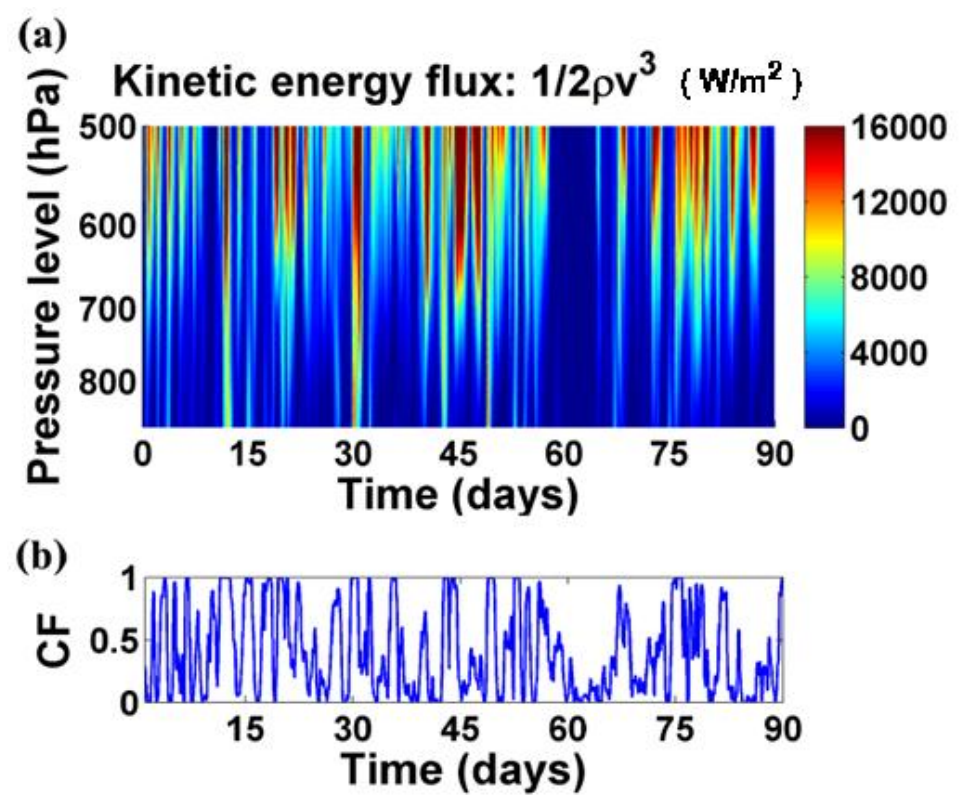

Fig. 2. (a) Variation of the vertical profile of the kinetic energy flux per square meter in the free atmosphere between $870 \mathrm{hPa}$ to $500 \mathrm{hPa}$ above the a grid cell near the City of Chicago $\left(42{ }^{\circ} \mathrm{N}\right.$, $88.7^{\circ} \mathrm{W}$ ) between period Dec 12004 to Feb 28 2005. (b) Variation of CF for a wind farm located in the vicinity of Chicago $\left(42^{\circ} \mathrm{N}, 88.7^{\circ} \mathrm{W}\right)$ over the period Dec 12004 to Feb 282005 . 
The evolution of the transient waves, defined as the deviation from the seasonal mean of the geopotential height at $500 \mathrm{hPa}$ is illustrated in the Figure 3a. Evolution of the corresponding values of CF, starting at 3:00 AM, Dec 30, 2004 is presented in Figure 3b. In these two snapshots separated by 15 hours, as the high pressure system (the red-colored wave pattern) moves east, the pattern of the instantaneous CF progresses in the same direction. The passage of the transient waves is responsible for the low frequency variability of the boundary layer wind [15-17] and for the corresponding variation in $\mathrm{CF}$. The spatial scales of the transient waves at $500 \mathrm{hPa}$ and patterns of the instantaneous CF are comparable in size to that of the continental US.

(a)
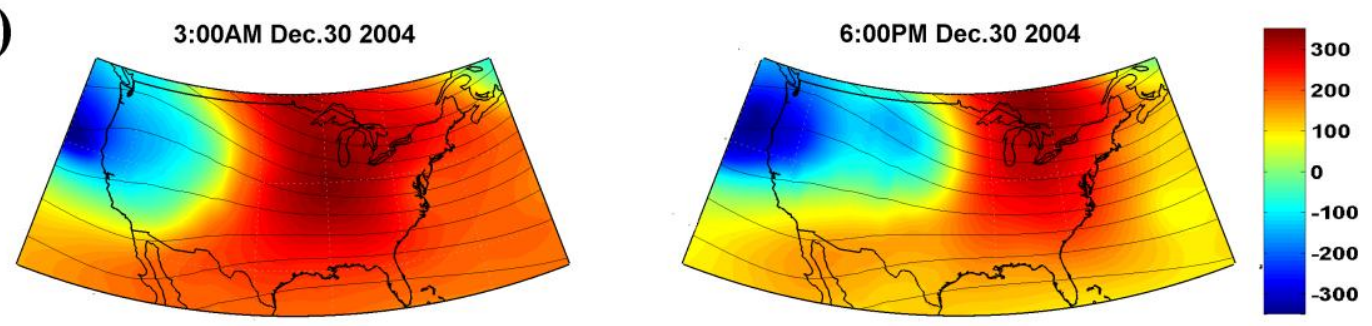

(b)
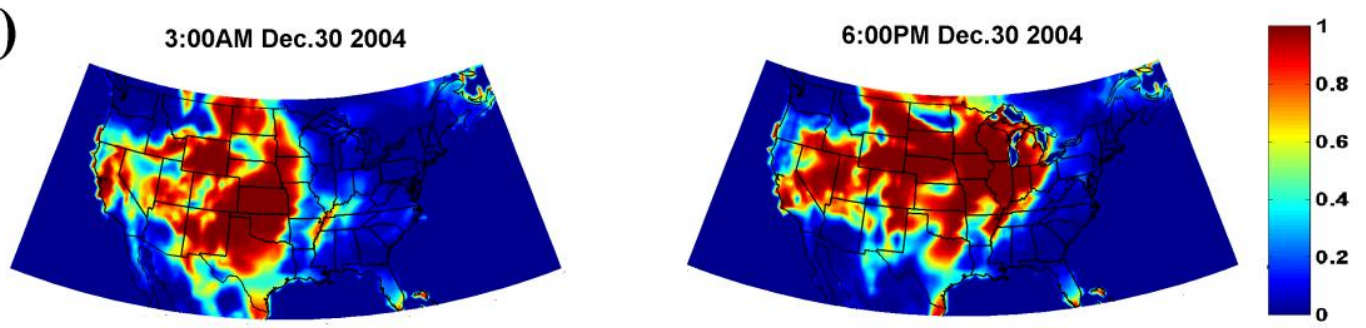

Fig. 3. (a) Snapshot of the departure of geopotential heights from the mean for two specific times. The contours indicate the seasonal mean of geopotential heights at $500 \mathrm{hPa}$. The color defines the deviation from the seasonal mean of the geopotential height. (b) summarizes the corresponding values for $\mathrm{CF}$. 


\subsubsection{Physical nature of the transient waves}

The physical nature of the transient waves can be elaborated using a simple model accounting for the changing patterns of the geopotential height and the wind speed at $500 \mathrm{hPa}$ together with the variation of the wind at $100 \mathrm{~m}$, as discussed for example by Holton and Hakim [15] and Wallace, et al. [16]. For mid latitude transient waves:

$$
\overrightarrow{V_{g}}=\frac{1}{f} \cdot \vec{k} \times \nabla(\mathrm{g} \cdot \mathrm{z})
$$

where $\overrightarrow{V_{g}}$ is the wind velocity in the free atmosphere (e.g. at the $500 \mathrm{hPa}$ level), $\mathrm{f}$ is the Coriolis parameter, $\mathrm{z}$ is the geopotential height (e.g. at the $500 \mathrm{hPa}$ level), and $\overrightarrow{\mathrm{k}}$ is the unit vector directed upward. Variations of wind velocities in the free atmosphere respond primarily to fluctuations in geopotential height. The wind velocity in the boundary layer $($ e.g. $100 \mathrm{~m})$ is determined by $\overrightarrow{V_{g}}$ in the free atmosphere as modified by random small scale turbulence generated in response to surface roughness. The dynamical sequence is as follows: transient waves $\mathrm{z}$ determine $\overrightarrow{\mathrm{V}_{\mathrm{g}}} ; \overrightarrow{\mathrm{V}_{\mathrm{g}}}$ sets the surface wind; the surface wind in turn determines CF.

A set of videos is included (videos 1 - 4) illustrating the changing patterns of the geopotential height and the wind speed at $500 \mathrm{hPa}$ together with the time and spatial variation of the wind and related $\mathrm{CF}$ values at $100 \mathrm{~m}$.

Video 1. The changing patterns of the variations in geopotential height and wind speed at 500 $\mathrm{hPa}$ together with the time and spatial variation of the wind and related values for $\mathrm{CF}$ values at $100 \mathrm{~m}$ in spring 2007 (Mar $1^{\text {st }} \sim$ May $31^{\text {st }}$ ). Upper left, the geopotential height at $500 \mathrm{hPa}$. Colors represent the instantaneous deviation from the seasonal mean. Contours with spatial resolution of $50 \mathrm{~m}$ indicate the seasonal mean of the geopotential height. Upper right, the instantaneous 500 
$\mathrm{hPa}$ wind speed. Bottom left, the instantaneous surface wind at $100 \mathrm{~m}$. Bottom right, the related instantaneous $\mathrm{CF}$ at $100 \mathrm{~m}$.

Video 2. The same as Movie 1 , but for summer 2007 (Jun $1^{\text {st }} \sim$ Aug $31^{\text {st }}$ ).

Video 3. The same as Movie 1, but for fall 2007 (Sep $1^{\text {st }} \sim$ Nov $30^{\text {st }}$ ).

Video 4. The same as Movie 1 , but for winter $2007\left(\right.$ Dec $1^{\text {st }} \sim$ Feb $28^{\text {st }}$ ).

3.1.3 Spatial Influence of Transient Waves. The relative coherence of meteorological conditions over the Central Plains region, specifically in winter when the transient waves are most intense, can be illustrated by considering spatial patterns in the cross-correlation of key meteorological parameters such as the geopotential height of the $500 \mathrm{hPa}$ surface, a representative diagnostic of conditions in the free atmosphere. We choose as reference for this purpose the temporal variation of the mean value of the geopotential height at $500 \mathrm{hPa}$ from 30 ${ }^{\circ} \mathrm{N}$ to $45^{\circ} \mathrm{N}$ latitude along a longitude of $98.125{ }^{\circ} \mathrm{W}$ straddling the region of interest. Geopotential heights are evaluated throughout the region every 3 hours for the 5 winters considered here (Dec 12002 - Nov 30 2007) with a spatial resolution of 5/4 ${ }^{\circ}$ latitude by 5/4 ${ }^{\circ}$ longitude. The cross-correlation between the time series of the $500 \mathrm{hPa}$ height and the reference height is calculated at each grid point as a function of time lag. The data are used then to calculate the time shift required to maximize the correlation between the two records. The magnitude of the cross-correlation computed on the basis of the time shift is illustrated in Figure 4a. Values derived for time shifts defining maximum cross correlation as a function of location are indicated, with a temporal resolution of 3 hours, by the contours in the figure. The figure clearly illustrates the coherence of the meteorological conditions influencing weather over an extended region of the central US in winter. The arrow indicates the average direction of 
propagation for the transient waves responsible for the observed variability. The time required for the waves to transit the region is approximately 1.5 days reflecting an average propagation speed of about $30 \mathrm{~km} / \mathrm{hour}$.

(a)Propagation of $500 \mathrm{hPa}$ waves in winter

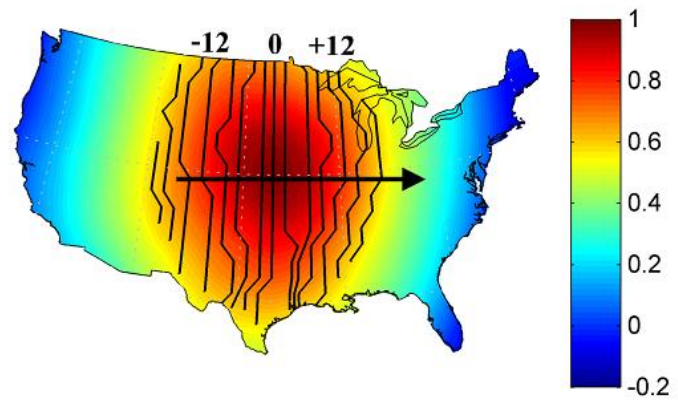

\section{(b) Propagation of $\mathrm{CF}$ values in winter}

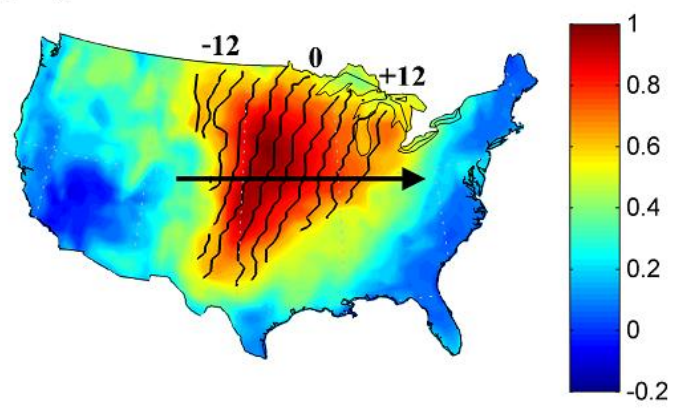

Fig. 4. (a) Wave propagation at $500 \mathrm{hPa}$ in winter. The contours indicate the time the waves take to propagate. The interval between two contour lines is 3 hours. The color defines the magnitude of the associated cross-correlation. The arrow points to the direction of propagation of the transient waves. The numbers indicate the lag time in units of hours relative to the reference. (b) Similar to 3a but for $\mathrm{CF}$ at $100 \mathrm{~m}$.

A similar approach may be used to evaluate the variation of conditions at $100 \mathrm{~m}$, the hub height for the GE 2.5 MW turbines considered here. We choose in this case to calculate the variation of the $\mathrm{CF}$ for GE 2.5 MW turbines distributed over the entire region of interest. The reference 
longitude is taken to be $98{ }^{\circ} \mathrm{W}$, roughly the same as for the analysis summarized in Figure 4a. Lags corresponding to the maximum cross-correlation for $\mathrm{CF}$ are indicated by the contours. Details of the approach are discussed further in SI, which includes also results for the propagation of the boundary layer wind at $100 \mathrm{~m}$. The difference in the overall pattern observed in Figure $4 \mathrm{~b}$ as compared to Figure $4 \mathrm{a}$ reflects the impact of the variability in surface roughness associated with mountainous regions to the west in combination with forested regions to the southeast.

Transient waves propagating from west to east dominate conditions in the free atmosphere, while surface features are influenced by fronts, the near surface component of the transient wave systems, traveling typically from northwest to southeast. This accounts for the slanted nature of the contours in Figure 4b. Results for two representative grid cells are presented in SI.

Figure 4 indicates that the Central Plains region is under the influence of the large scale transient waves. Electricity generated by one wind farm located in the Central Plains region is not independent of the electricity output from another wind facility in the same region. The transient waves link all the wind farms in the region of interest here. Thus the effectiveness of interconnection in reducing the low frequency variability has a limit determined by the inherent variability of the transient waves.

\subsection{Effectiveness of interconnection}

3.2.1 Creating a Portfolio of Wind Farms. The spatial scale of boundary layer turbulence is relatively small, compared to the spatial scale associated with the transient waves. It is relatively easier therefore to compensate through wind farm interconnection for the variation of wind energy attributable to this small scale turbulence. The more challenging task is to reduce the 
variation of wind energy associated with the transient waves. The transient waves normally propagate from west to east. If their spatial scale and speeds were determined and fixed, coupling wind farms in the west-to-east direction would offer an optimal strategy. However, the waves behave stochastically in their movement and spatial scale [15-17], especially in summer, as illustrated in videos 1-4.

The region of interest for this study covers approximately $(1250)^{2} \mathrm{~km}^{2}$. We consider a portfolio of $\mathrm{N}$ wind farms, with installed capacities adjusted to ensure equal (annual) production of electricity from each, distributed uniformly over this region. The average separation between individual wind farms is given then by $1250 / \mathrm{N}^{1 / 2} \mathrm{~km}$. For any particular value of $\mathrm{N}$, we consider 100 randomly selected options for location of the $\mathrm{N}$ individual farms. We assume that the power output from the $\mathrm{N}$ farms can be coupled. The expectation is that the variability in output from individual farms can be offset to some extent by out of phase variability at others.

In integrating wind energy into electrical grids, larger wind power swings pose challenges in matching supply with demand. The effective use of intermittent sources hinges on the stability of their power outputs. In this paper, we use estimates of relative standard deviation (RSD) to measure the stability of wind, with small RSD indicating stability, and vice versa. The RSD computed for the $\mathrm{CF}$ of the coupled system is presented as a function of season for a range of values of $\mathrm{N}$ in Figure 5. Each point in the figure reflects a specific choice of siting for the individual wind farms (100 possibilities for each value of N). Fits to the average values of the standard deviations computed for different values of $\mathrm{N}$ are indicated by the continuous curves in the figure. RSD's for low values of $\mathrm{N}$ are large approaching $100 \%$ in some cases. Mean values of RSD decrease rapidly as a function of increasing $\mathrm{N}$, approaching a relatively constant value for $\mathrm{N}$ greater than about 10 . As $\mathrm{N}$ increases, the high frequency variability associated with random 
boundary layer turbulence can be effectively reduced, and the wide geographic distribution of the wind farms serves to capture the intrinsic variability associated with the propagation of the transient waves through the region.
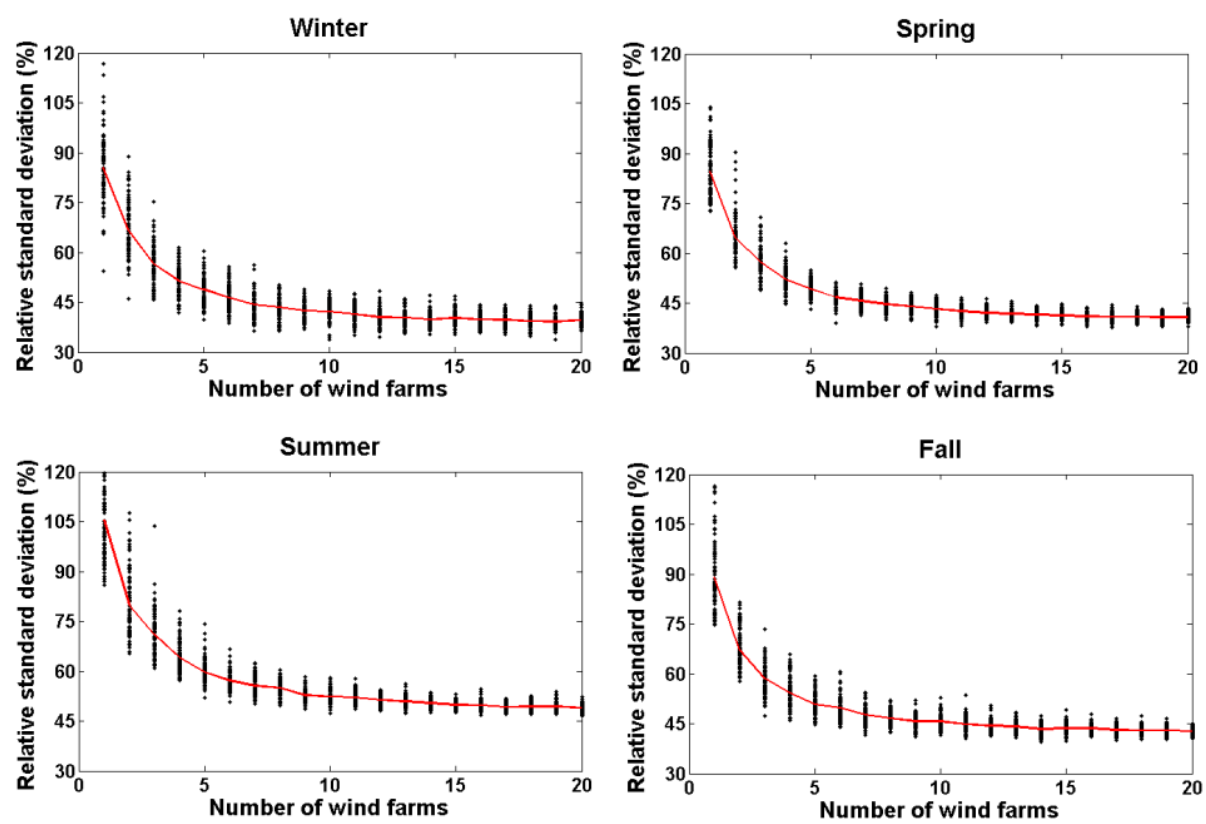

Fig. 5. Relative standard deviation (RSD) for CF (\%) for all four seasons as a function of the assumed number of wind farms $(\mathrm{N})$. Individual data points reflect 100 possible location options for each value of $\mathrm{N}$.

The temporal variability of the power output from the region of interest considered here can be minimized by combining outputs from approximately 5-10 spatially distributed wind farms. The decrease in the RSD of the coupled system as a function of $\mathrm{N}$ as indicated in Figure 5 reflects this condition. There is a limit however to the decrease in system variance that can be realized by coupling multiple wind farms. This absolute limit, approximately $45 \%$ for each season for the region considered here, is determined by the intrinsic variability of the transient waves. 
3.2.2 Benefit of Interconnection. To directly illustrate the benefit that could be realized by combining wind farms, we consider ten farms, one per state, distributed over the study region as indicated in Figure 1 with installed capacities adjusted to ensure equal (annual) production of electricity from each of these installations. The temporal variation of the capacity factor for one of these installations, No. 5 located in Nebraska, is compared in Figure 6 with the output that could be realized by coupling all ten farms. Figure 6 summarizes results derived for all four seasons over the interval Dec 12004 to Nov 30 2005. The output from individual stations varies between zero and full power over times as brief as a few hours. In contrast, the output from the combined system is less variable. Peak values of CF for the composite system are typically lower than those for individual farms, and the combined system avoids the zero power condition encountered frequently for individual stations. Though not completely eliminating the variability problem, the coupled system mitigates the associated management pressure on operation of the grid. Values for the RSD of CF as a function of season are summarized for individual wind farms and for the combined system in Figure 7. 

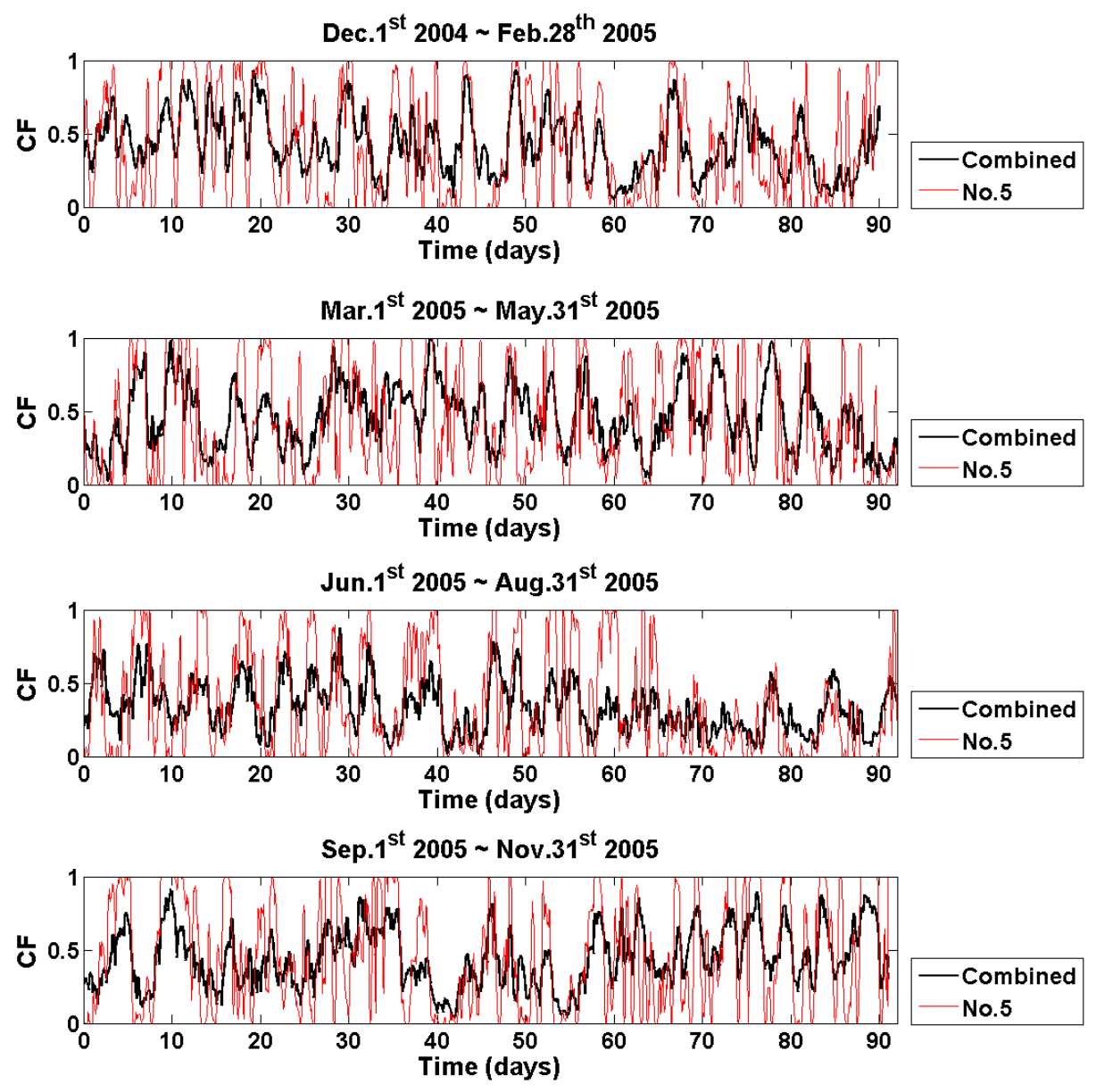

Fig. 6. Variation of CF series for wind farm No.5 and for the combined system over the period Dec 12004 to Nov 302005.

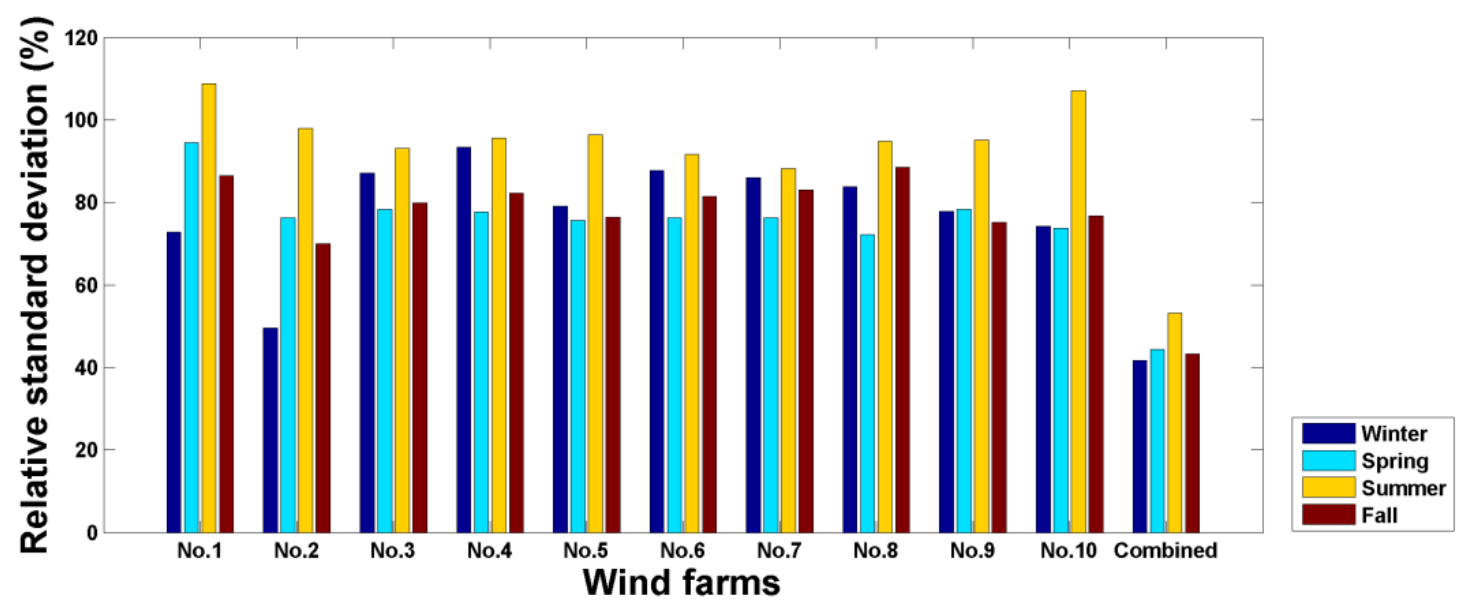

Fig. 7. RSD of CF for all the ten wind farms and the combined system. 
Outputs from the combined system and for wind farm No.5 are presented in the form of probability distributions for $\mathrm{CF}$ in Figure 8 . The results summarized here cover the entire 5-year period Dec 12002 - Nov 30 2007. Results for one year period, similar to those displayed in Figure 8, are presented in SI. The variability of the output from a single farm is evidenced by the almost uniform distribution of CF values in Figure 8a (including peaks at zero and one). In contrast, the probability distribution for the combined system displays a distinct peak at 0.35 with a broad tail extending to high values of $\mathrm{CF}$, with a low probability for $\mathrm{CF}$ values less about 0.1. The results in Figure 8 can be presented equivalently in terms of what is referred to as a duration curve $[9,12]$, the fraction of the time for which the wind farm can achieve an output exceeding a particular value of $\mathrm{CF}$ as a function of CF. Duration curves for wind farm No.5 and for the combined system are presented in SI. The RSD of CF is approximately $100 \%$ for individual wind farms - greater in summer, less in winter. The RSD for the combined system is much less, approximately $45 \%$ independent of season. The pattern observed for the on-shore system investigated here is similar to that reported earlier for the off-shore Atlantic system considered by Kempton et al [11]. 


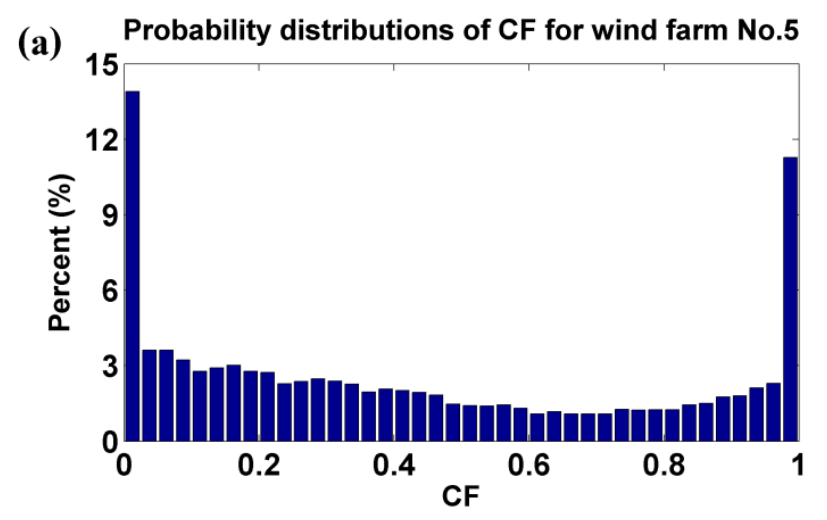

(b) Probability distributions of CF for the combined system

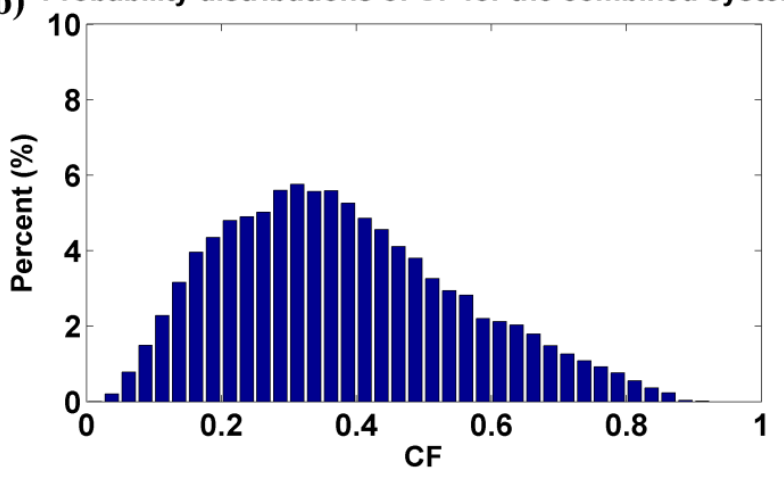

Fig. 8. (a) Probability distributions of CF for wind farm No.5. (b) Probability distributions of $\mathrm{CF}$ for the combined system.

Results for individual seasons are presented in Figure 9. The seasonal dispersion of values for the integrated system is significantly less for all four seasons than the dispersion observed for a particular location. For the combined wind system in summer, the peak of probability distribution shifts toward lower values of $\mathrm{CF}$, reflecting a weaker general circulation and a reduced role for the propagation of transient waves in summer time.

The frequency spectrum for the variation in the power output of the combined system is presented for all four seasons in Figure 10. The variability is concentrated primarily on time scales greater than a day. The importance of the diurnal frequency is evident in the figure, particularly for summer. Results are displayed in terms of cumulative variance in Figure 11, 
emphasizing again the importance of the variability at low frequency (longer time scales) for the combined system in contrast to the more extensive range of frequencies associated with the output from a single facility. More than $90 \%$ of the variance of the combined system is concentrated at frequencies less than 0.5 day $^{-1}$, periods longer than 2 days.

(a)
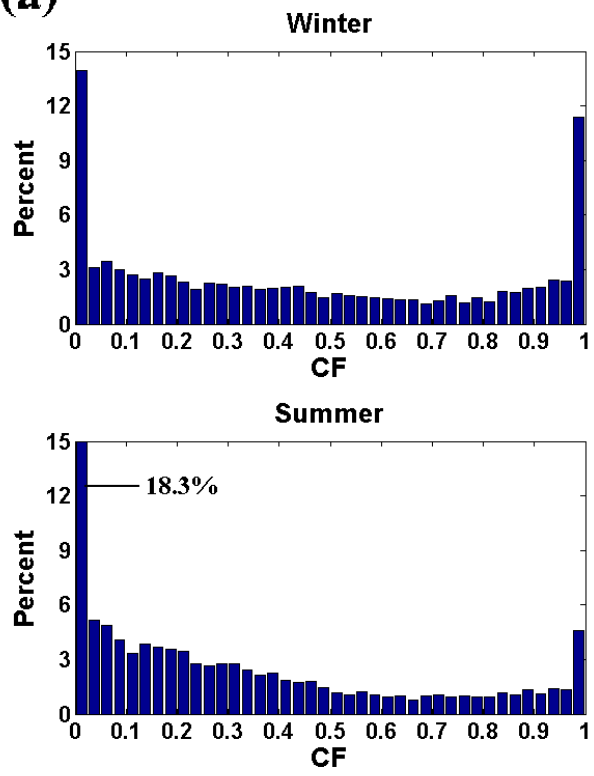

(b)
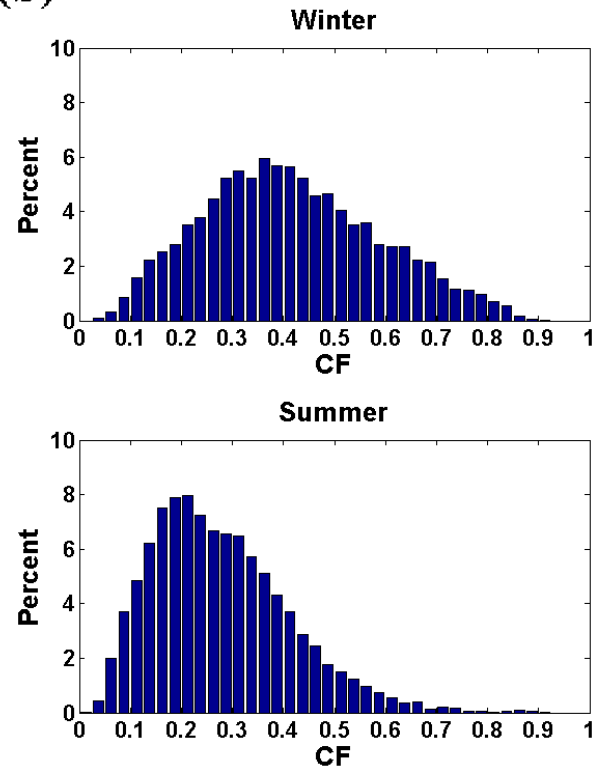
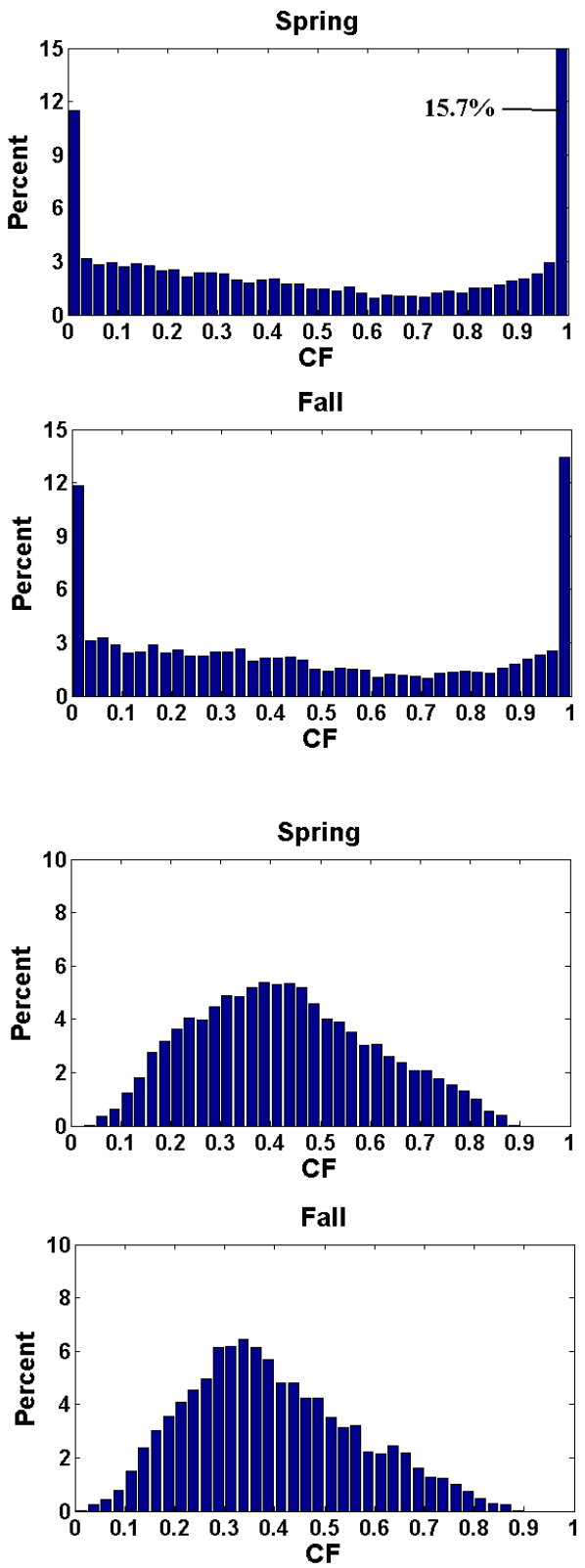

Fig. 9. (a) CF histogram for wind farm No. 5 as a function of season. (b) CF histogram for the combined wind system as a function of season. 
As indicated earlier, high frequency variability is associated with small scale turbulence in the boundary layer: the smaller the scale of the turbulence, the shorter its lifetime [16]. The high frequency variability evident for a single station can be compensated effectively by comparable though uncorrelated high frequency variability at other stations. Effective elimination of the high frequency variability would allow for easier scheduling of power output from the integrated system, taking advantage of the availability and increased reliability of multi-day forecasts for regional wind conditions.
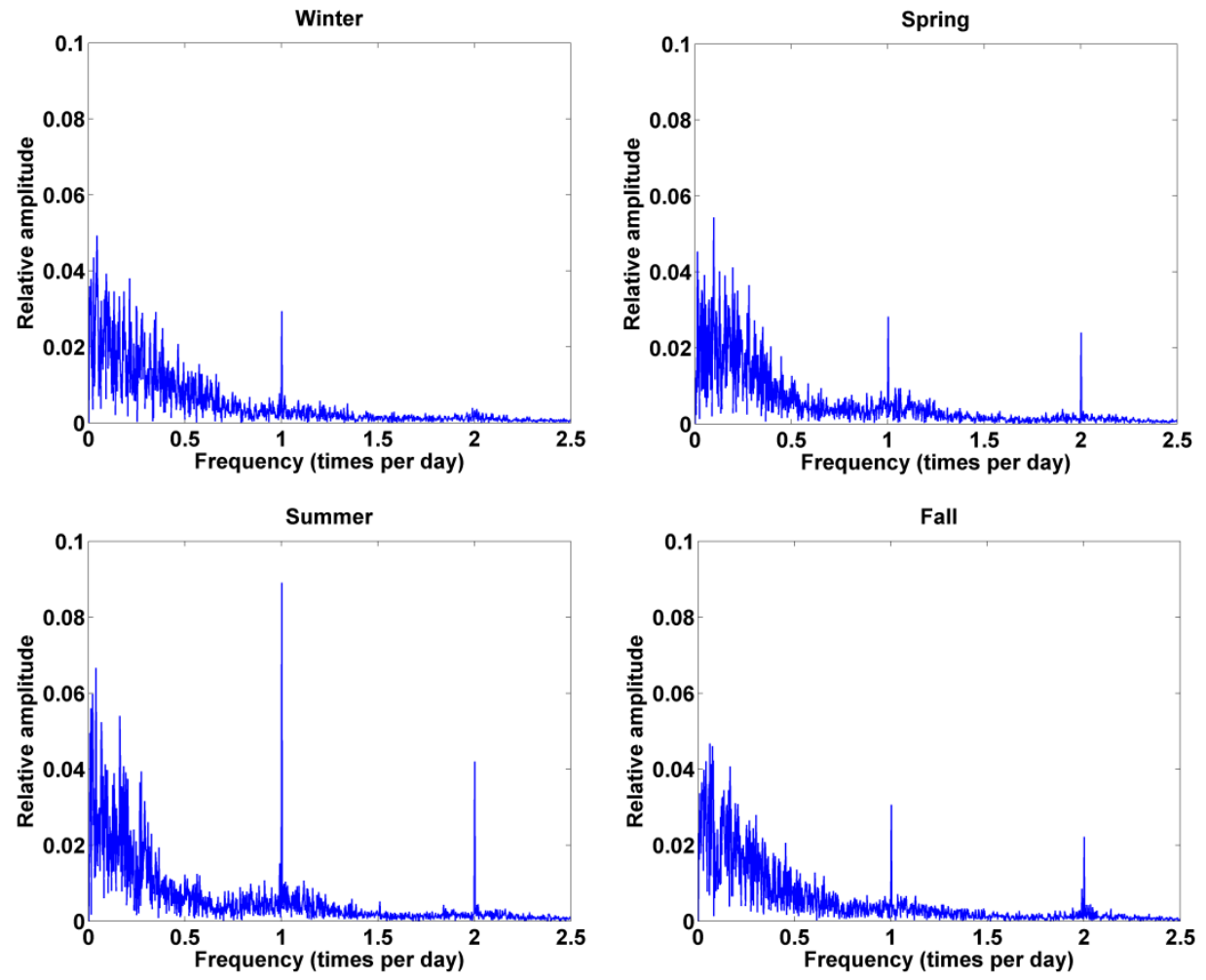

Fig. 10. Relative amplitude spectrum of wind power (normalized to 1) for the four seasons for the integrated system. For a specific frequency, the square of the amplitude represents its contribution to the total variability. 


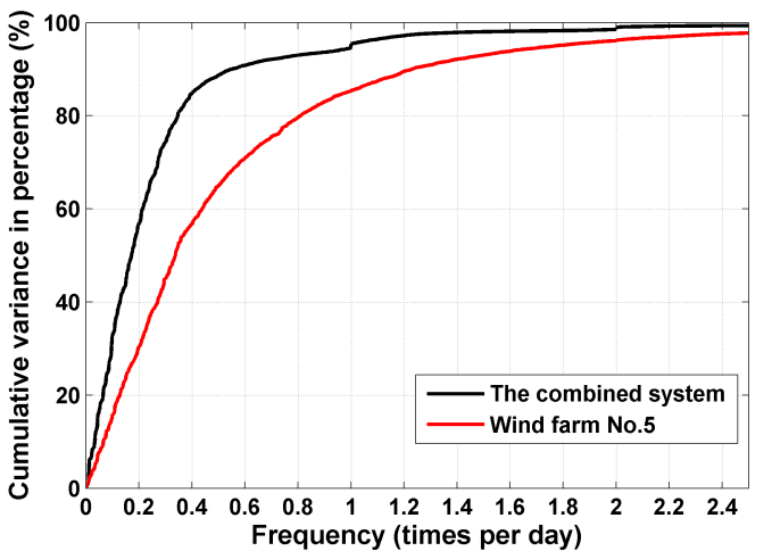

Fig. 11. Cumulative variance of annual power output as a function of frequency for the combined system and wind farm No.5.

3.2.3 One-point correlation analysis. Many studies addressing the opportunities and challenges of interconnection have sought to define empirically the correlation in wind output between different sites $[2,6,10,19]$. A number of papers have reported that coupling wind farms in the east-to-west direction will be more efficient than coupling in the north-to-south direction, arguing that the correlation of energy outputs between individual wind farms decreases faster as a function of distance in east-west direction $[2,6]$.

Transient waves propagate generally in the west-to-east direction. If the waves were regular and their movements were perfectly periodic, correlation of energy outputs from two wind farms should decrease slowly in the north-to-south direction. As indicated by video 4 and figure 4 , the pattern of propagation of transient waves in winter falls closer to this ideal situation. However, transient waves in other seasons (videos 1-3) are more stochastic: there is no general function available to explain the correlation between separated wind farms in these cases. 

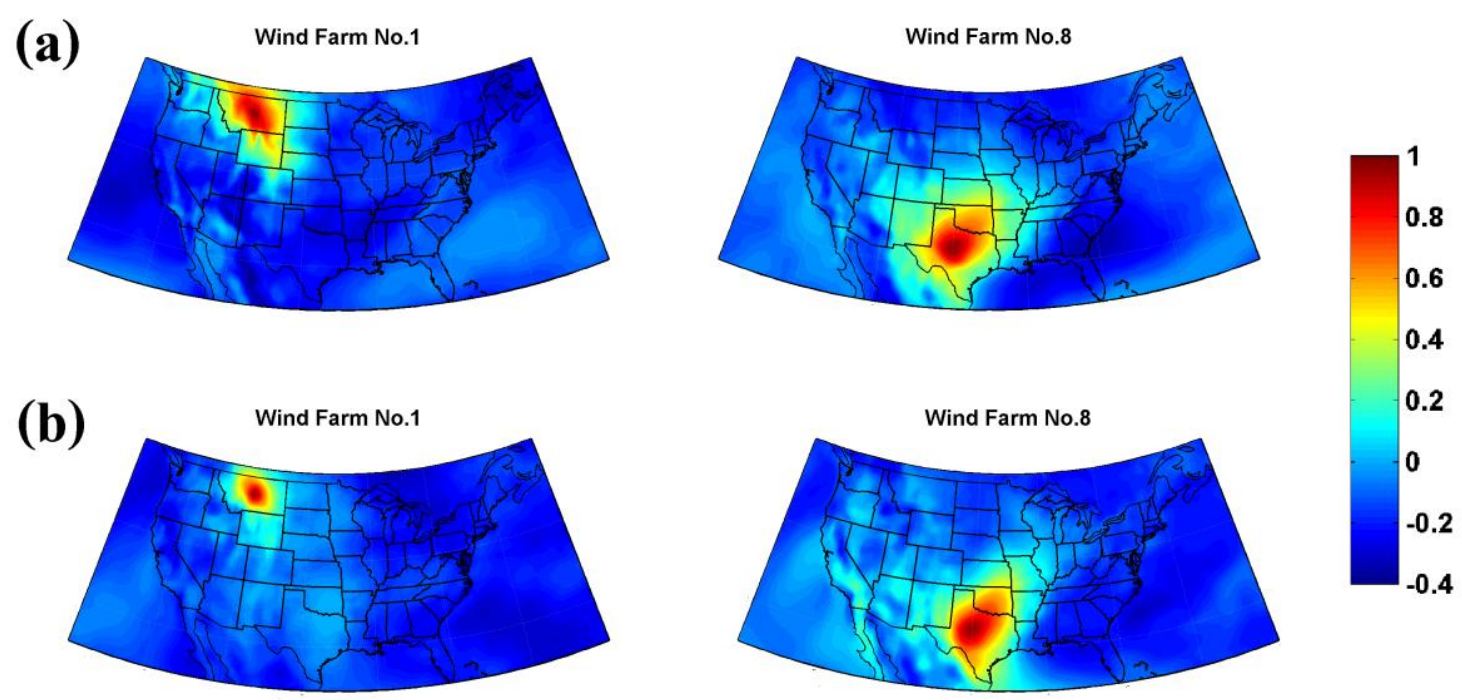

Fig. 12. (a) One-point correlation of power output for two different wind farms in winter. (b) One-point correlation of power output for two different wind farms in summer.

Figure $12 \mathrm{a}$ and $12 \mathrm{~b}$ summarize correlations between hourly values of $\mathrm{CF}$ computed over the entire region with results obtained for two specific locations (wind farms No. 1 and 8 located in the states of Montana and Texas). Results in Figure 12a cover winter conditions over the five year interval from Dec 1, 2002 to Nov 30, 2007. Corresponding results for the five summers are included in Figure 12b. The results indicate that local meteorological conditions differ from place to place and from season to season. Consider Wind Farm No.1 in winter. The prevailing wind in the free atmosphere is strong and from northwest to southeast in this case [16]. The onepoint correlation decreases slowly in the northwest to southeast direction. In the case of Wind Farm No.8, the prevailing wind in the free atmosphere is from southwest to northeast [16]. As a consequence, the one-point correlation decreases slowly in the southwest-to-northeast direction in this case.

\section{Discussion}


Fertig, et al. [14] argued that fluctuations in wind power are not white noise, based on frequencydomain analysis. The high frequency variability of outputs from individual wind farms is determined, however, mainly by small scale boundary layer turbulence associated with local conditions; the low frequency variability is associated with the passage of transient waves with a characteristic time scale of several days. Fertig, et al [14] also concluded that the interconnection of wind plants within a single region would further reduce the ratio of fast- to slow-ramping generators. The physical explanation is associated with the impact of boundary layer turbulence: high frequency variance is determined by boundary layer turbulence, the spatial scales of which are small and the related variance can be smoothed by coupling generation systems within a single region. Coupling wind farms within a single region can reduce the high frequency variability of electricity output, and provide relatively slowly varying energy output.

Czisch, et. al [7] pointed out that the correlation of energy outputs from two wind farms will increase if the high frequency variations of their energy outputs are filtered. The filtered energy output eliminates the signal introduced by boundary layer turbulence, while retaining the information imparted by transient waves. Because the spatial scale of the transient waves is large, the correlation calculated with the smoothed data should be enhanced.

Archer and Jacobson [12] considered the advantages that could be realized by interconnecting wind farms over a region of $850 \mathrm{~km}$ by $850 \mathrm{~km}$ including parts of Colorado, Kansas, Oklahoma, New Mexico, and Texas. They found that an average of 33\% wind power from interconnected farms could be exploited as reliable, baseload electric power. The continental US is located at mid-latitudes in a meteorological regime dominated by the influence of transient waves $[15,16]$. In our study, the lag-correlation analysis indicates that the whole Central Plains region is under the influence of these transient waves. Electricity generated by one wind farm located in the 
Central Plains region is not independent of the power output from another wind facility in the same region. There is a limit therefore to the effectiveness of interconnection determined by the inherent variability of the transient waves.

Although this study focused on the meteorology of wind energy in the US, the method and findings can be applied to other regions. Oswald [8] argued that while the aggregate output of a distributed wind system in the United Kingdom is smoother than the output of individual wind farms or individual regions, the power delivered by such an aggregate wind fleet is highly volatile. Surface winds in the UK are also determined by the interaction of transient waves with the local boundary layer turbulence. The UK is located downwind of the Atlantic Ocean. Transient waves there are more volatile and stronger. Since the spatial scale of the UK is smaller than that associated with the transient waves, interconnection in this case is relatively ineffective in smoothing the variance contributed by those large scale waves.

Simonsen and Stevens's [6] statistical analysis indicated a more rapid decrease in correlation over the east-west direction as compared to the north-south direction in the Central United States, a conclusion that is generally consistent with typical east-west direction for the passage of transient waves in that region. Based on wind data for Texas, Katzenstein, et. al [10] also tried to establish a function explaining wind farm correlation. However, the behaviors of transient waves are relatively regular in winter, stochastic in summer. The one-point correlation analysis in this study underscores the fact that there is no general function available to define the correlation of two wind farms. Local meteorological conditions determine the correlation of individual farms and may differ from place to place and from season to season. In the case of Texas (Wind Farm No. 8) in winter, Figure 12 indicates a more rapid decrease in correlation in 
the northwest-southeast direction. In the case of Montana (Wind Farm No. 1) in winter, Figure 12 implies that the correlation decreases most rapidly in the northeast-southwest direction.

This study explored the strategy for an optimal deployment of a coupled system: 5 10 wind farms distributed uniformly over the Central Plains region of the US. The high frequency variability of a coupled system can be effectively eliminated. As indicated though, the low frequency variability is determined by passage of the transient waves' characteristic of meteorological conditions in this region. Interconnection alone cannot completely eliminate the challenges associated with the variability of wind-generation power, which is limited fundamentally by properties of the large scale transient waves. Effective elimination of the high frequency variability, however, would allow for easier scheduling of power output from the integrated system, taking advantage of the increased availability and reliability of multi-day forecasting for regional wind conditions.

The temporal and spatial resolutions of the data have an impact on the variability analysis. In the real situation, the energy output from a wind farm will fluctuate at much higher frequencies than those shown by our hourly wind data, but this only reinforces the points made in the manuscript. The boundary layer wind is influenced by the transient waves and the boundary layer conditions. The latter factor generates random small scale and short term turbulences. Coupling wind farms will be effective in cutting down high frequency noise attributable to this random turbulence, but ineffective in reducing the inherent variability of the transient waves. Since we use hourly data with a spatial resolution of $1 / 2^{\circ}$ latitude by $2 / 3^{\circ}$ longitude here, in which fluctuations at time scales shorter than an hour and spatial scales smaller than the resolution are ignored, the high frequency noise is underestimated in our analysis. The effectiveness of interconnection should be 
even more conspicuous than what we estimate in this article, in the sense that high frequency variability should be eliminated to an even greater extent.

\section{ACKNOWLEDGMENT}

The work described here was supported by the National Science Foundation under grant ATM-

1019134 to Harvard University. Junling Huang was also supported by the Harvard Graduate Consortium on Energy and Environment. 


\section{REFERENCES}

1. X. Lu, M.B. McElroy, J. Kiviluoma, Global potential for wind-generated electricity. Proc. Natl. Acad. Sci. 106(2009), 10933-10938. DOI: 10.1073/pnas.0904101106

2. 20\% Wind Energy by 2030: Increasing Wind Energy's Contribution to U.S. Electricity Supply; United States Department of Energy: Washington, DC, 2008; http://www.nrel.gov/docs/fy08osti/41869.pdf

3. W. Short, N. Blair, D. Heimiller; V. Singh, Wind Power 2003 Conference, Modeling the long-term market penetration of wind in the United States, ed Christine RA (American Wind Energy Association, Austin, TX), 2003; p 11.

4. G.M. Masters, Renewable and Efficient Electric Power Systems; A John Wiley \& Sons, Inc.: Hoboken, NJ, 2004.

5. E. Kahn, The reliability of distributed wind generators. Electr. Pow. Syst. Res. 2(1979), $1-14$.

6. T.K. Simonsen, B.G. Stevens, Regional wind energy analysis for the Central United States. Proc. Global. Wind. Power. (American Wind Energy Association, Chicago) 2004; p 16.

7. G. Czisch, B. Ernst, High wind power penetration by the systematic use of smoothing effects within huge catchment areas shown in a European example. Windpower 2001 (American Wind Energy Association, Washington, DC), 2001.

8. J. Oswald, M, Raine, H. Ashraf-Ball, Will British weather provide reliable electricity? Energy Policy, 36(2008), 3202-3215.

9. H. Holttinen, R. Hirvonen, Power system requirements for wind power. Wind Power in Power Systems, T. Ackermann, Ed., John Wiley and Sons, 2005; pp143-167.

10. W. Katzenstein, E. Fertig, J. Apt The variability of interconnected wind plants. Energy Policy, 2010, 38, 4400-4410.

11. W. Kempton, F.M. Pimenta, D.E. Veron, B.A. Colle, Electric power from offshore wind via synoptic-scale interconnection. Proc. Natl. Acad. Sci. 107(2010), 7240-7245. DOI: 10.1073/pnas.0909075107

12. C.L. Archer, M.Z. Jacobson, Supplying Baseload Power and Reducing Transmission Requirements by Interconnecting Wind Farms. J. Appl. Meteorol. Clim. 46(2007), 17011717. DOI: $10.1175 / 2007 J A M C 1538.1$ 
13. E.K. Hart, M.Z. Jacobson, A Monte Carlo approach to generator portfolio planning and carbon emissions assessments of systems with large penetrations of variable renewables, Renewable Energy 36(2011), 2278-2286.

14. E. Fertig, et al. "The effect of long-distance interconnection on wind power variability." Environmental Research Letters 7.3 (2012): 034017.

15. J.R. Holton, G.J. Hakim, An introduction to dynamic meteorology, Academic press, 2012, pp 256-276.

16. J.M. Wallace and P.V. Hobbs. Atmospheric science: an introductory survey. Vol. 92. Academic press, 2006, pp 313-413

17. I.N. James, Introduction to circulating atmospheres. Cambridge University Press, 1995, pp 112-207.

18. X. Lu, M.B. McElroy; N. Sluzas, Costs for Integrating Wind into the Future ERCOT System with Related Costs for Savings in $\mathrm{CO}_{2}$ Emissions. Environmental Science \& Technology 45 (2011): 3160-3166.

19. G. Giebel, 2000. On the benefits of distributed generation of wind energy in Europe. $\mathrm{Ph}$.D. Dissertation, Carl von Ossietzky University of Oldenburg, 2000, 104 pp. Available at: 〈http://www.drgiebel.de/GGiebel_DistributedWindEnergyInEurope.pdf $\rangle$. 